\title{
Characterization of the oxidation resistance property of SiAION materials with the standard method of GB/T 32329-2015
}

\author{
Xiu-Teng WANG ${ }^{1, a}$, Yajing ZHANG ${ }^{2}$, b ${ }^{*}, \mathrm{Pu} \mathrm{XIAO}^{3}$, Bo WANG ${ }^{3}$, Ling XU ${ }^{3}$, Ling \\ $\operatorname{LIN}^{1}$, Jin HUANG ${ }^{1}$ \\ ${ }^{1}$ Subinstiture of Resource and Environment, China National Institute of Standardization, Beijing, \\ 100191, P. R. China \\ ${ }^{2}$ College of Information Science and Technology, Beijing University of Chemical Technology, \\ Beijing, 100029, P. R. China \\ ${ }^{3}$ College of Engineering, Peking University, Beijing, 100871, P. R. China

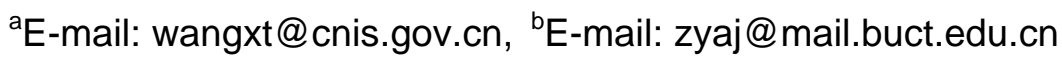

Keywords: SiAION, oxidation resistance, non-isothermal testing method, standard, GB/T 32329-2015.

\begin{abstract}
The oxidation resistance is one of the most important properties of refractory materials. China national standard GB/T 32329-2015, which title is "Test method for oxidation resistance of oxynitride materials-non-isothermal oxidation”, provide a standard characterizing method for oxidation resistance. In our work we validate this standard and test the oxidation resistance of six SiAlON samples using this method. The oxidation resistance property of oxynitride materials could be well described with these indicators: the oxidation weight gain per unit area, the initial oxidation temperatures and the maximum oxidation rate temperatures. From the experimental results we conclude that this standard is scientific and feasible.
\end{abstract}

\section{Introduction}

SiAlON ceramics are light, hard and strong engineering ceramics, which were discovered in the early 1970s [1-3]. They can withstand harsh environments and support heavy loads at temperatures beyond those at which metals and polymers fail. SiAlON ceramics are one kind of the commercially produced high-tech ceramic materials due to their excellent physical properties. Especially, it is a specialist class of high-temperature refractory materials, with high strength at high temperature, good thermal shock resistance and exceptional resistance to wetting or corrosion by molten non-ferrous metals, compared to other refractory materials such as, for example, alumina. A typical use is with handling of molten aluminium. They also are exceptionally corrosion resistant and hence are also used in the chemical industry.

SiAlONs also have high wear resistance, low thermal expansion and good oxidation resistance up to above $\sim 1000^{\circ} \mathrm{C}$. When SiAlONs are used as refractory materials, the oxidation resistance is one of attention-getting properties, because the oxidation resistance will determine the best use temperature and other use conditions.

In order to establish a set of common testing methods, Standardization Administration of the People's Republic of China (SAC) issued a national standard in 2015. The number of this standard is GB/T 32329-2015, and the title is "Test method for oxidation resistance of oxynitride materials - non-isothermal oxidation”. This standard was developed based on the fact that the weight of SiAlONs will increase due to the oxidation reaction under high temperature. The standard provides the characterization of the oxidation resistance of SiAlONs in the non-isothermal oxidation process through thermogravimetry method [4-6].

In this work, we characterize the oxidation resistance of one SiAlON material synthesized in our lab with the standard test method of GB/T 32329-2015. Experimental results show that the standard method can characterize the oxidation resistance of this refractory material with good operability. 


\section{Experimental Section}

Apparatus. TGA-16 Thermo Gravimetric Analyzer made by Sinosteel Luoyang Institute of Refractories Research, China.

Experimental. Six test samples were taken from the bulk material. According to GB/T 32329-2015, we take the following experimental steps [7].

1) Preparation of samples. After the bulk product was obtained, 6 rectangular samples were cut out from the bulk material with the size of $(25 \pm 1) \mathrm{mm}$ (Length) $\times(25 \pm 1) \mathrm{mm}$ (Width $) \times$ $(10 \pm 1) \mathrm{mm}$ (Height). Clean up the furnace to ensure that the furnace does not contain high temperature volatile matter, as well as acid, alkali and other pollutants. Check and confirm that the temperature control instrument is in normal condition.

2) Rub off the specimen burrs, clean the surface of the specimen. Dry it and cool it down to room temperature in the dryer, weighing it as $m_{1}$.

3) Dry the corundum crucible until its weight remains constant, cooling it in the dryer to room temperature. Place the sample into the center of the corundum crucible so that the contact area of the specimen and the crucible as minimal as possible. Place the crucible with the specimen hanging in the constant temperature zone of a heating furnace.

4) Import continuous air flow into the heating furnace with the rate of $1 \mathrm{~L} / \mathrm{min}$.

5) Heat up the furnace with the same temperature-control procedure shown in Table 1 . The data of temperature and the sample weight were recorded automatically and synchronously. First, with the air was continuously injected in, the corundum crucible was heated from room temperature to $800^{\circ} \mathrm{C}$ at the rate of $10^{\circ} \mathrm{C}$ per min, then to $1100^{\circ} \mathrm{C}$ at the rate of $8^{\circ} \mathrm{C}$ per min, and to the maximum temperature $\left(T_{\max }\right) 1500^{\circ} \mathrm{C}$ at the rate of $4{ }^{\circ} \mathrm{C}$ per min. After that the sample chamber remained at $1500^{\circ} \mathrm{C}$ for $120 \mathrm{~min}$. The holding time is $t$.

Table 1. Heating rate in the whole testing process

\begin{tabular}{|c|c|}
\hline Temperature range & Heating rate \\
\hline Room temperature $~ 800^{\circ} \mathrm{C}$ & $10^{\circ} \mathrm{C} / \mathrm{min}$ \\
\hline $800^{\circ} \mathrm{C} \sim 1100^{\circ} \mathrm{C}$ & $8^{\circ} \mathrm{C} / \mathrm{min}$ \\
\hline $1100^{\circ} \mathrm{C} \sim 1500^{\circ} \mathrm{C}$ & $4^{\circ} \mathrm{C} / \mathrm{min}$ \\
\hline
\end{tabular}

6) After that, stop heating and stop the air import. Then the heating furnace with the specimen was cooled down to $50{ }^{\circ} \mathrm{C}$, and put in the dryer cooling to room temperature, weighing the sample as $m_{2}$.

\section{Results and Discussion}

Total surface area. The sizes and the total surface area $(S)$ of the 6 samples are shown in Table 2.

Table 2. Sizes and total surface area of the samples

\begin{tabular}{ccccc}
\hline Sample Number & $\begin{array}{c}\text { Length } \\
(L, \mathrm{~mm})\end{array}$ & $\begin{array}{c}\text { Width } \\
(W, \mathrm{~mm})\end{array}$ & $\begin{array}{c}\text { Height } \\
(H, \mathrm{~mm})\end{array}$ & $\begin{array}{c}\text { Total surface area } \\
\left(S, \mathrm{~mm}^{2}\right)\end{array}$ \\
\hline SiAlON-1 & 24.20 & 15.00 & 15.00 & 1902.00 \\
SiAlON-2 & 23.75 & 15.00 & 14.40 & 1828.50 \\
\hline SiAlON-3 & 24.55 & 14.70 & 15.00 & 1899.27 \\
SiAlON-4 & 24.50 & 15.00 & 14.85 & 1908.15 \\
\hline SiAlON-5 & 24.50 & 15.00 & 14.85 & 1908.15 \\
SiAlON-6 & 24.15 & 15.30 & 15.00 & 1922.49
\end{tabular}

The sample weight difference $(\Delta m)$ was calculate as Eq. 1 according to the weight at any temperature $(m)$ and the value at room temperature $\left(m_{1}\right)$. 


$$
\Delta m=m-m_{1}
$$

And then, the relative weight change $\left(R_{\mathrm{m}}\right)$ is calculated as Eq. 2.

$$
R_{m}=\frac{\Delta m}{m_{0}} \times 100 \%
$$

The oxidation weight gain per unit area $(G)$ can be calculated from the final weight gain $(\triangle M)$ and the total surface area of the sample $(S)$ as Eq. 3 and the results are shown in Table 3.

$$
G=\frac{\Delta M}{S}
$$

Table 3. The oxidation weight gain per unit area of 6 samples

\begin{tabular}{cccc}
\hline & $\Delta M(\mathrm{~g})$ & $S\left(\mathrm{~mm}^{2}\right)$ & $G\left(\mathrm{mg} / \mathrm{mm}^{2}\right)$ \\
\hline SiAlON-1 & 0.48 & 1922.49 & 0.25 \\
SiAlON-2 & 0.36 & 1828.50 & 0.19 \\
\hline SiAlON-3 & 0.49 & 1899.27 & 0.26 \\
SiAlON-4 & 0.52 & 1908.15 & 0.27 \\
\hline SiAlON-5 & 0.51 & 1908.15 & 0.27 \\
SiAlON-6 & 0.50 & 1902.00 & 0.26
\end{tabular}

According to the data of the sample weight and temperature, the curves between $R_{\mathrm{m}}$ and $T$ could be drawn. First order differential of the curves between $R_{\mathrm{m}}$ and $T$ result in the oxidation weight gain rate curve ( $\left.\mathrm{d} R_{\mathrm{m}} / \mathrm{d} T\right)$. The peak of $\mathrm{d} R_{\mathrm{m}} / \mathrm{d} T$ curve corresponds to the temperature with maximum rate of oxidation, which is denoted as $T_{2}$.

The tangent line at the temperature of $T_{2}$ in the curves between $R_{\mathrm{m}}$ and $T$ intersects with the baseline. The corresponding temperature at the intersection point, denoted as $T_{1}$, is defined as the initial oxidation temperature.

The curves of $R_{\mathrm{m}} v s T$ and $\mathrm{d} R_{\mathrm{m}} / \mathrm{d} T$ vs $T$ of $\quad 6$ SiAlON samples are given in Fig. 1.

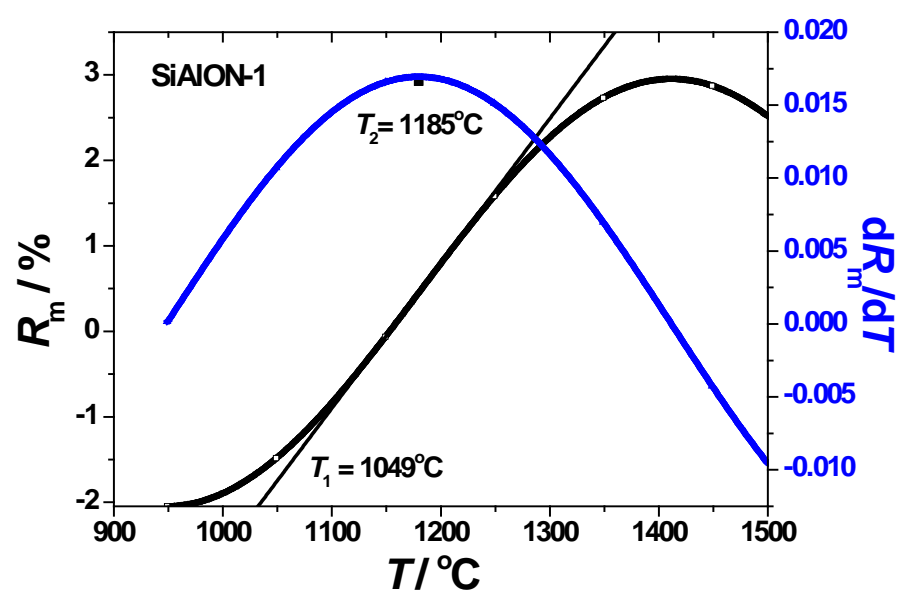

(a) 


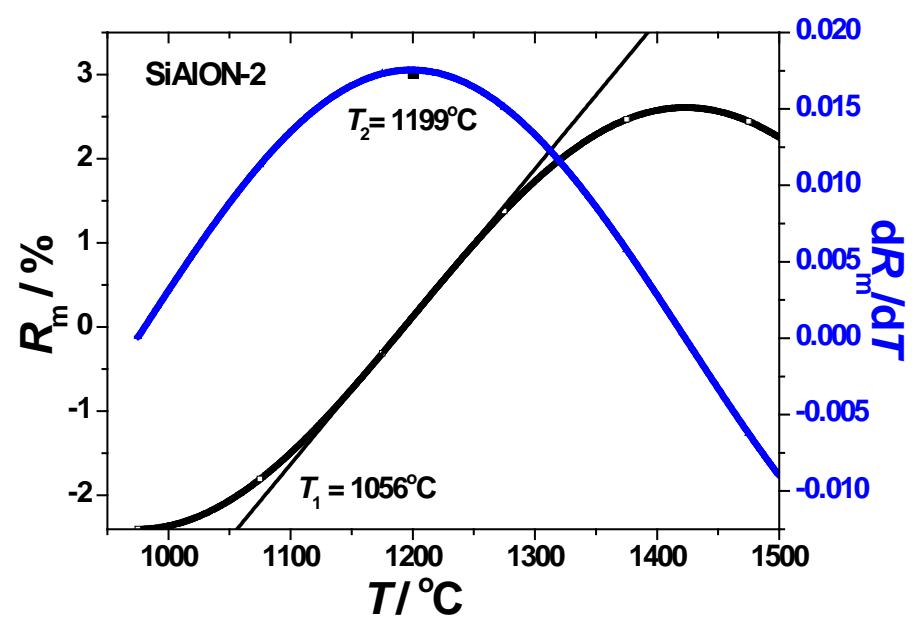

(b)

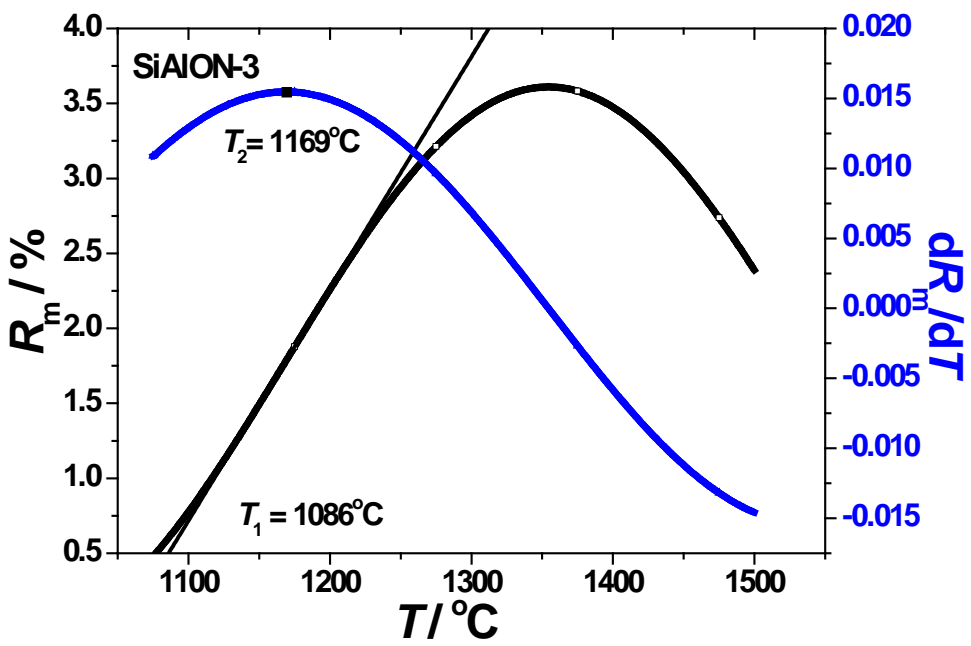

(c)

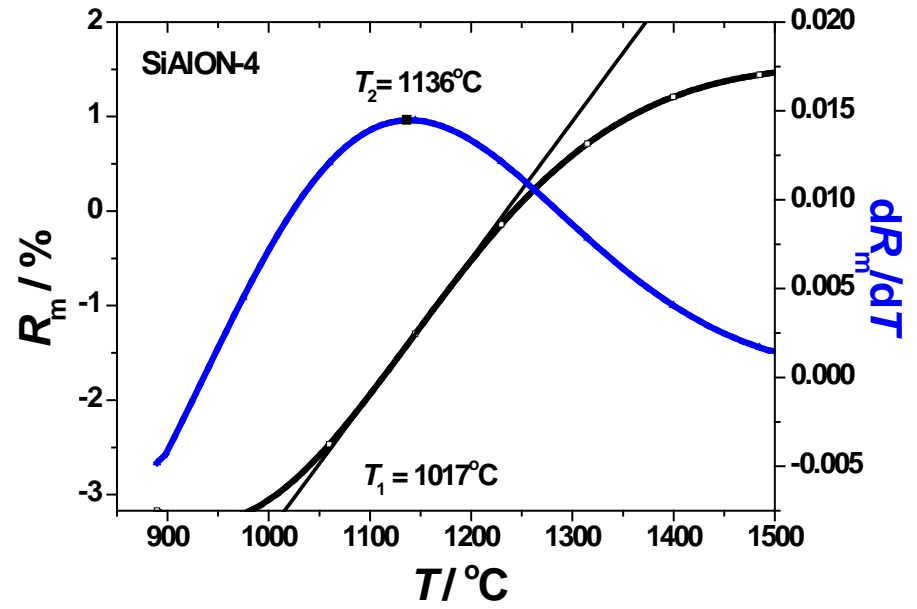

(d) 


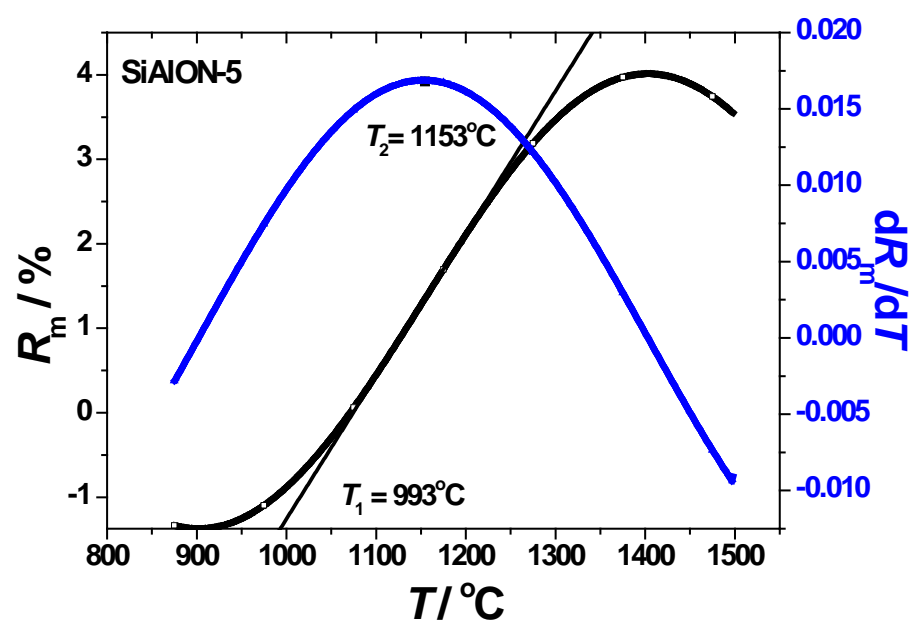

(e)

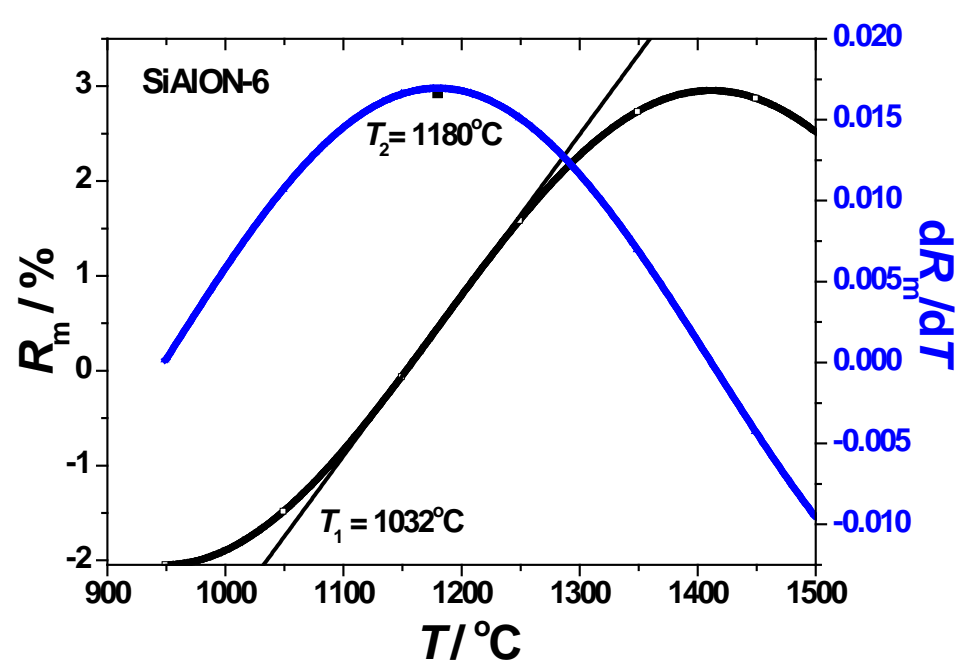

(f)

Fig. 1. The $R_{\mathrm{m}} v s T$ and $\mathrm{d} R_{\mathrm{m}} / \mathrm{d} T$ vs $T$ curves of the 6 SiAlON samples. (a): SiAlON-1; (b): SiAlON-2; (c): SiAlON-3; (d): SiAlON-4; (e): SiAlON-5; (f): SiAlON-6.

The initial oxidation temperatures $\left(T_{1}\right)$ and the maximum oxidation rate temperatures $\left(T_{2}\right)$ were obtained as Table 4.

Table 4. The initial oxidation temperatures and the maximum oxidation rate temperatures of the six samples

\begin{tabular}{ccccc}
\hline & $T_{1}\left({ }^{\circ} \mathrm{C}\right)$ & $\bar{T}_{1}\left({ }^{\circ} \mathrm{C}\right)$ & $T_{2}\left({ }^{\circ} \mathrm{C}\right)$ & $\bar{T}_{2}\left({ }^{\circ} \mathrm{C}\right)$ \\
\hline SiAlON-1 & 1032 & 1044 & 1180 & 1190 \\
SiAlON-2 & 1056 & & 1199 & 1153 \\
\hline SiAlON-3 & 1086 & 1052 & 1169 & 1169 \\
SiAlON-4 & 1017 & & 1136 & \\
\hline SiAlON-5 & 993 & 1021 & 1153 & 1180 \\
SiAlON-6 & 1032 & & & \\
\hline
\end{tabular}


The average values of the initial oxidation temperature and the maximum oxidation rate temperature for the SiAlON material we prepared are $1036{ }^{\circ} \mathrm{C}$ and $1171{ }^{\circ} \mathrm{C}$, respectively. And the average oxidation weight gain per unit area is $0.25 \mathrm{mg} / \mathrm{mm}^{2}$.

\section{Summary}

GB/T 32329-2015 provides a standard method of characterization of the oxidation resistance of oxynitride materials in the non-isothermal oxidation process through thermogravimetry. We test the oxidation resistance of 6 SiAlON samples using this standard method. From the experimental results it is concluded that this standard is scientific and feasible and the oxidation resistance property of oxynitride materials could be well described with these indicators: the oxidation weight gain per unit area, the initial oxidation temperatures and the maximum oxidation rate temperatures.

\section{Acknowledgements}

This work was financially supported by the National Science and Technology Support Programs of China (2011BAB02B05) and 863 Program (2012AA06A117).

\section{References}

[1] K. H. Jack and W. I. Wilson: Nature Phys. Sci. (London), Vol. 238 (1972), p. 28-29.

[2] K. H. Jack: Trans. J. Brit. Ceram. Soc., Vol. 72 (1973), p. 376-378.

[3] Y. Oyama and K. Kamigaito: Jpn. J. Appl. Phys, Vol. 10 (1971), p. 1637-1642.

[4] X.D. WANG, F.M. WANG and W.C. LI: Journal of Inorganic Materials, Vol. 1 (2003), p. 83-90.

[5] X.M. HOU, G.Z. ZHOU: Journal of the Chinese Ceramic Society, Vol. 6 (2007), p. 778-781.L.

[6] WANG, M.X. JIANG, H.F. YIN, P.J. CHEN, B.T. LI: Bulletin of the Chinese Ceramic Society, Vol. 2 (2012), p. 332-335.

[7] GB/T 32329-2015 Test method for oxidation resistance of oxynitride materials—non-isothermal oxidation. 